\title{
The Role of Field Margins in Agro-biodiversity Management at the Farm Level
}

\author{
Giulio Lazzerini ${ }^{* 1}$, Alessandra Camera $^{2}$, Stefano Benedettelli ${ }^{1}$, Concetta Vazzana ${ }^{1}$ \\ ${ }^{1}$ Dipartimento di Scienze Agronomiche e Gestione del Territorio Agroforestale \\ ${ }^{2}$ Dipartimento di Biotecnologie Agrarie \\ Università di Firenze, Piazzale delle Cascine 18, 50144 Firenze, Italy
}

Received: 2 December 2006. Accepted: 2 January 2007

\begin{abstract}
The agroecosystem could be considered as a mosaic so large to involve fields with annual and perennial crops, pastures, spots of wildwood, semi-natural habitats, vegetation in the edges of fields. In the agroecosystem these ecological infrastructures have a positive effects on the crops because of the exchange among community of organisms, materials and energy.

The aim of this research is to evaluate the effects of field margins on some biodiversity components (plant species and carabid beetles) of four farms located in Val d'Orcia (Tuscany). We compared three types of field margins: 1. Cultivated margin strips; 2 . Sown grass margin strips; 3 . Wild margin strips with hedgerow. In a very simplified typology of farming system, like the one studied (Val d'Orcia), the presence of field margins (hedges, margin strips and semi-natural habitats associated with the boundary) is very important for its ecological effects: it improves the planned biodiversity, gives habitat, refuge, food and corridors for the movement to the different species of organisms in the area.

Applying the multivariate analysis to the experimental data, we can notice a positive effect of the presence of field margins on the trend of both components of biodiversity. This positive effect, which support the mechanisms of autoregulation of the agroecosystems, is very important especially for organic and biodynamic agriculture, where the use of pesticides is not allowed.
\end{abstract}

Key-words: agroecosystem, biodiversity, field margin.

\section{Introduction}

A high proportion of biodiversity exists on land dedicated to the production of food: thus agricultural intensification is the principal cause of biological simplification of the farm environment. The level of biodiversity in the different agroecosystems depends on several elements: the kind of vegetation within and around the field; the crop rotation; the input intensity of the farming system and the level of isolation of the agroecosystem from the wild species (Southwood and Way, 1970).

Especially in organic agriculture, farms need a more complex agroecosystem structure, with semi-natural habitats and field margins, which consist of hedgerows or some other structures, such as wild or sown grass margin strips in the hedge bottom (Hole et al., 2005; Lazzerini et al., 2004).
Greaves and Marshall (1987) define "a field margin" as "whole of the crop edge, any margin strip present and the semi-natural habitat associated with the boundary". The different habitats found in field margins give food (prays/hosts), water, refuge, favourable microclimate, shelter from pesticides and a winter reproduction site for natural enemies of pests. The kind of vegetation around field margins has a different effect on the presence and efficiency of useful insects. Lewis (1965) asserts that hedgerows give hospitality to a larger diversity of entomofauna than the neighbouring crops and that some types of hedgerows can improve the population of useful insects within a certain distance. The typology of boundary, for example, is strongly correlated with the presence of carabids, which prefer more complex ecological 
infrastructures, such as hedgerows, than field margins or strips covered with grasses (Sotherton, 1984).

In a simplified farming system, the presence of "field margins" is very important to improve the components of biodiversity (flora and fauna). Some researches provide evidences that non crop habitats (areas with natural or sowed plants suitable as refuge and winter site for predators) offer dispersal corridors and islands in otherwise fragmented landscape. Different are the proposals for the creation of these areas: for example, using narrow raised ground strips around fields (Thomas e Wratten, 1990) or creating 3-8 metres large "strips" with wild plants every 50-100 metres (Nentwing, 1988). These strips are defined "ecological compensation areas" and permit to increase the biodiversity of insects and allow to bolster natural predator populations (Soil Association, 1999). Some researchers established grass strips in autumn-winter cereal crops: one of the results was the increasing of genetic diversity and richness of spiders and carabid insects (Helenius et al., 1995; Sunderland and Samu, 2000; Altieri et al., 2003).

Because the management of agricultural systems can dramatically affect overall levels of biodiversity, as well as the success of particular species, the purpose of the present research is to establish the effects of different kinds of field margins on flora and fauna (carabids) components of 4 agroecosystems characterized by different management.

\section{Materials and methods}

\subsection{Characteristics of the studied farms}

The research was performed in 4 different farms located in Val d'Orcia (SI) - South of Tuscany. In this agricultural area, farming is mainly based on cereals as a part of short rotation schemes; landscape is very unusual and homogeneous, with a few ecological infrastructures.

Of the studied farms, one is conventional (farm 1), one is a farm in conversion to organic (farm 2) and the last two are organic (farm 3 and 4). Farms 1 and 3 are of limited size, with a few ecological infrastructures, while farms 2 and 4 are of medium-large size and richer as to natural and seminatural habitats (Tab. 1).

In each of the farms the effect of the presence of field margins was studied. The considered typologies of field margins are the following:

1. Cultivated margin strips (farms 1 and 4)

2. Sown grass margin strips (farms 2 and 3 )

3. Wild margin strips with hedgerow (farm 4).

In the different strips, a sampling of vegetation was conducted in the period between April and June (years 2004 and 2005) throwing randomly a square metal frame $(0.25 \times 0.25 \mathrm{~m})(6$ repetition for strip) (Vazzana and Raso, 1997). The soil macrocrofauna (carabid beetles) sampling was conducted on the different field margins during the year 2004 between March and June, using for each strip three couples of pitfall traps (6 traps in total) at $50 \mathrm{~m}$ distance, every traps at $10 \mathrm{~m}$ from the others (Fig. 1). Five samplings were carried out. All collected beetles were identified. Data were used to elaborate flora and fauna indicators: species richness defined as $\mathrm{S}=\mathrm{n}_{\mathrm{i}}$, where $\mathrm{n}_{\mathrm{i}}=$ species $\mathrm{i}$ (Vereijken, 1995) and a diversity indicator defined as $\mathrm{H}^{\prime}=$ $\mathrm{p}_{\mathrm{i}} \log _{2} \mathrm{p}_{\mathrm{i}}$, where $\mathrm{p}_{\mathrm{i}}=$ frequency of the species $\mathrm{i}$ (Shannon and Weaver, 1963).

\subsection{Statistic analysis methods}

The aim of the statistic analysis was to correlate the presence of different type of field margins with the richness and diversity of flora and fauna. Plant species have been classified each

Table 1. Principal characteristics of the four studied farms.

\begin{tabular}{lcccc}
\hline & Conventional farm & Farm in conversion to & Organic farm & Organic farm \\
& $(1)$ & organic $(2)$ & $(3)$ & $(4)$ \\
\hline Total Surface (ha) & 36.5 & 168.5 & 37.3 & 207.0 \\
Crop surface (ha) & 31.6 & 133.7 & 34.6 & 149.0 \\
Rotation & no & Biennial & Biennial & Biennial \\
Pesticide use & yes & no & no & no \\
Type of fertilizers & Mineral & Organic & Organic & Organic \\
Percentage wild areas (\%) & 3.8 & 18.6 & 5.2 & 24.9 \\
\hline
\end{tabular}


one within a biological group (Montegut, 1982): Therophyte (Th), Hemicryptophyte (Hr), Geophyte $(\mathrm{G})$, rhizomatous Geophyte (Gdr-rh) (Catizone and Zanin, 2001).

The aggregation of carabid beetles was based on their diet; in fact, the kind of food seems to be the main element for the choice of habitat (Kromp, 1999). Therefore, carabids have been classified as granivorous, spermophagous, predators, polyphagous.

Multivariate analysis were carried with: nometric Multi- Dimensional Scaling (MDS), Cluster Analysis (CA), Principal Component Analysis (PCA) using the Primer 6 program (Clarke and Warwick, 1994). The first two methods start from a matrix of similarity coefficient (BC) (Bray and Curtis, 1957).

The Bray-Curtis coefficient (BC) is given:

$$
B C_{i k}=100\left\{1-\frac{\sum_{i=1}^{p}\left|y_{i j}-y_{i k}\right|}{\sum_{i=1}^{p}\left(y_{i j}+y_{i k}\right)}\right\}
$$

Where $\mathrm{BC}_{\mathrm{jk}}$ is the similarity between the $\mathrm{jth}$ and kjth sites, and yij represents the abundance for the ith species in th site.

The third method starts from the dissimilarity matrix of Euclidean distances (Chatfied and Collins, 1980).

For the MDS and CA the Anosim test (analysis of similarity) shows the R statistic that is a useful comparative measure of the degree of separation of sites: if $\mathrm{R}=1$ all replicates within sites are more similar to each other that any replicates from different sites; if $\mathrm{R}$ is approximately zero the null hypothesis is true, so that similarities between and within sites will be

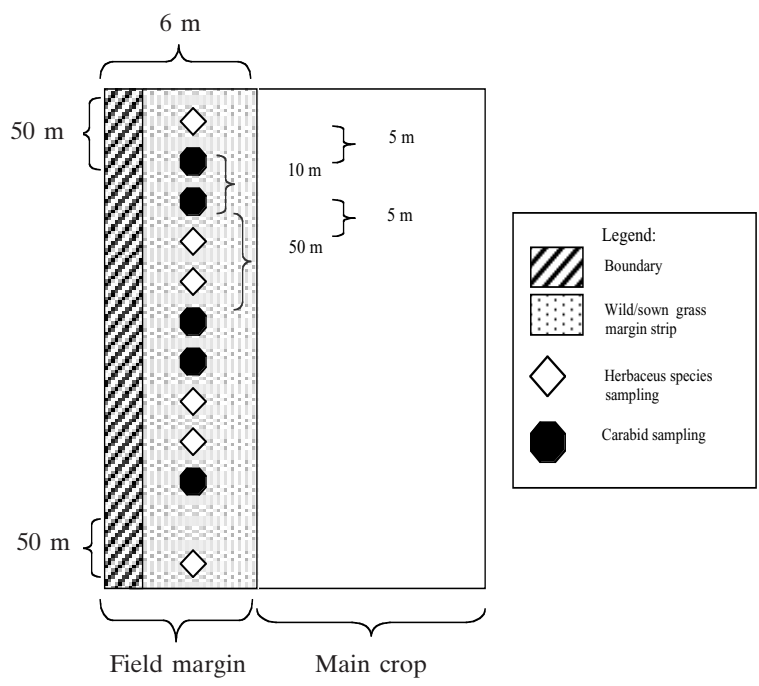

Figure 1. Sampling of the two biodiversity components of field margins.

same on average (Clarke and Warwick, 1994).

PCA analysis gives two results (Eigenvector and percentage of variance) which explain the firsts two principal components.

\section{Results and discussion}

\subsection{Plant species}

Table 2 shows the values of the biodiversity indicators (richness and species diversity) related to the flora and calculated for the 4 studied farms.

Both for 2004 and 2005 the highest species richness (30 species in 2004, 35 species in 2005) was found in the field margin of the organic farm "4" (plot 3112). This field margin is the

Table 2. Richness and diversity of herbaceous species found in field margins of the four studied farms (years 2004 and 2005).

\begin{tabular}{ccccc|cccc}
\hline Farm & $\begin{array}{c}\text { Plot } \\
\text { number }\end{array}$ & $\begin{array}{c}\text { Number } \\
\text { of Families }\end{array}$ & $\begin{array}{c}\text { Richness } \\
\text { of species }\end{array}$ & $\begin{array}{c}\text { Diversity } \\
(\mathrm{H})\end{array}$ & $\begin{array}{c}\text { Plot } \\
\text { number }\end{array}$ & $\begin{array}{c}\text { Number } \\
\text { of Families }\end{array}$ & $\begin{array}{c}\text { Richness } \\
\text { of species }\end{array}$ & $\begin{array}{c}\text { Diversity } \\
(\mathrm{H})\end{array}$ \\
\hline 1 & & \multicolumn{2}{c}{2004} & & & 2005 & \\
1 & 321 & 7 & 9 & 1.95 & 421 & 4 & 6 & 0.93 \\
2 & 323 & 6 & 6 & 0.91 & 423 & 5 & 5 & 1.08 \\
2 & 341 & 8 & 19 & 1.24 & 441 & 6 & 11 & 1.06 \\
2 & 342 & 8 & 16 & 1.85 & 442 & 4 & 10 & 1.01 \\
3 & 343 & 8 & 16 & 1.50 & 443 & 7 & 13 & 1.20 \\
3 & 312 & 6 & 21 & 2.02 & 412 & 7 & 19 & 1.95 \\
4 & 316 & 11 & 30 & 2.67 & 416 & 15 & 33 & 2.36 \\
4 & 331 & 11 & 16 & 1.77 & 431 & 9 & 19 & 2.04 \\
\hline
\end{tabular}


most complex, because of the presence of hedgerow and wild margin strip. The same positive effect has been obtained with a field margin of sown grass strip (plot 316) in the organic farm " 3 ". In fact in this field margin 30 species in 2004 and 33 in 2005 were found (Tab. 2). The lowest species richness for both years, was found in the conventional farm " 1 ", where field margins have only a cultivated strip (Tab. 2).

Many studies investigating the flora of arable and mixed farming systems recorded higher species richness in field under organic management (Frieben and Kopke, 1995; Hald, 1999). Several researches agree with these results and show the positive effects of field margins to the floristic composition (Frieben e Kopke, 1995; Aalto, 1998; Moonen and Marshall; 2001, Hole et al., 2005).

The same trend, for both years, was found quantifying species diversity using Shannon's index. The diversity index of field margin with hedgerow and wild strip (plot 3312) was 3.29 in 2004 and 2.7 in 2005 (Tab. 2). Shannon's index of field margin with sown grass strip (plot 316) was 2.67 in 2004 and 2.36 in 2005 (Tab. 2). The lowest value of diversity ( 0.93 ) was noticed for farm "1" and particularly in the year 2005 (Tab. 2).

\subsection{Carabid insects}

Table 3 shows the values of the biodiversity indicators (richness and species diversity) related to carabid beetles, calculated for the four farms studied in the present work. Several references underline the positive effects of wildflower strips on both the number of species and diversity of carabid insects (Feber, 1998; Thomas and Marshall, 1999). In agreement with them the highest species richness was found in the field margin with sown grass strip of the organic farm 3 (27 species in the field margin of plot 311 and 26 in the field margin of plot 316) (Tab. 3). The richness value (24) is high also in field margins with hedgerow and wild strip in the organic farm 4 (plot 3312) and in the farm 2 in conversion to organic (plot 341 and 342) (Tab. 3).

The lowest species richness was observed in the conventional farm 1 (plot 321 and 323) where field margins are cultivated margin strips (Tab. 3).

The highest value for Shannon's index (2.9)
Table 3. Richness and diversity of Carabid insects found in field margins of the four studied farms (year 2004).

\begin{tabular}{cccc}
\hline Farm & Plot number & $\begin{array}{c}\text { Richness of } \\
\text { species }\end{array}$ & Diversity (H) \\
\hline 1 & 321 & 20 & 2.4 \\
1 & 323 & 18 & 2.3 \\
2 & 341 & 24 & 2.6 \\
2 & 342 & 24 & 2.6 \\
2 & 343 & 23 & 2.6 \\
3 & 312 & 27 & 2.5 \\
3 & 316 & 26 & 2.5 \\
4 & 331 & 23 & 2.5 \\
4 & 337 & 19 & 2.1 \\
4 & 3312 & 24 & 2.9 \\
\hline
\end{tabular}

was observed in the field margin with hedgerow and wildflower strip of farm 3 (plot 3112) (Tab. 3). The value of the diversity Shannon's index is high also in the field margin in the farm 2 (2.6) for plot 341 and 342 (Tab. 2). The lowest diversity index was observed in field margins with cultivated strip of farms 1 and farm 4 (Tab. 3).

\subsection{Statistic analysis}

Plant species. Table 4 gives the eigenvalues and associated variances obtained using PCA for single species. The first two components explain around $86 \%$ of the total variance. The first eigenvector shows a positive correlation with

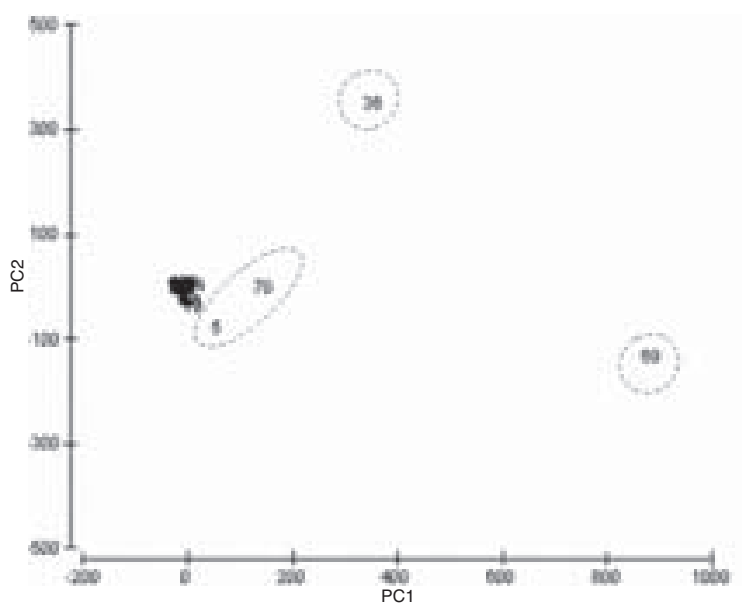

Figure 2. Principal Component Analysis (PCA) applied to single species of field margins of the four studied farms (year 2005). Numbers correspond to the following species: $5=$ Alopecurus myosuroides; $70=$ Lolium perenne; $36=$ Daucus carota; 69 = Lolium multiflorum (Percentage Variance $\mathrm{PC} 1=73.9 \% ; \mathrm{PC} 2=11.6)$. 


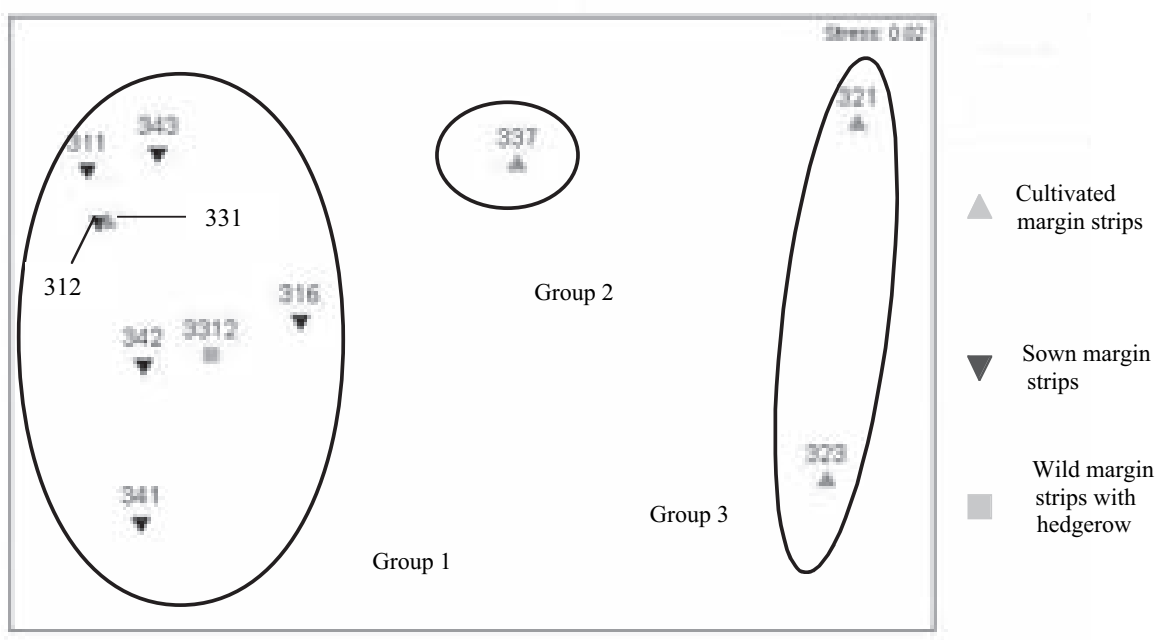

Figure 3. No-metric multi-dimensional scaling analysis (MDS) of herbaceous species classified into their biological group of field margins for the four studied farms (year 2004) based on the Bray-Curtis similarity coefficient (Stress 0.02). variables 441, 442, 443 e 4312. The second eigenvector shows a positive correlation with variables 443. PCA shows a group of plants living in field margins with hedgerow and old sown strips (Fig. 2).

Figure 3 displays the results of ordination by MDS based on similarity matrix of 9 sites. The generated stress value is 0.02 . According to Clarke and Warwick (1994) a stress $<0.05$ gives an excellent representation with no prospect of misinterpretation. MDS applied to species classified into biological groups shows, particularly in 2004, a group of plant species found in plots with field margins with sown grass strips of farms 2, 3 and 4 (group 1). This group involves Therophyte -Th and Hemicriptophyte - Hr species. These are species at higher level in the scale of evolution and their presence means a higher degree of stability of agroecosystem (Fig. 3). Groups 2 and 3 are related to plots with field

Table 4. Eigenvectors and percentage explained variance PCA of plant species (year 2005).

\begin{tabular}{ccc}
\hline Plot number & Eigenvectors I & Eigenvectors II \\
\hline 421 & 0.002 & -0.003 \\
423 & 0.013 & -0.012 \\
412 & 0.036 & -0.055 \\
416 & 0.030 & -0.161 \\
431 & 0.015 & -0.056 \\
434 & 0.036 & -0.081 \\
4312 & 0.201 & -0.223 \\
441 & 0.659 & -0.507 \\
442 & 0.320 & -0.302 \\
443 & 0.647 & 0.751 \\
Percentage Variance (\%) & 73.9 & 11.6 \\
\hline
\end{tabular}

margins with cultivated strips of farms 4 and 1 (Fig. 3).

Cluster analysis applied to plant species richness and diversity shows a diagram of similarity where plots are distributed according to the different type of field margins (Fig. 4). The first cluster involves plots with field margins represented by sown grass strips and wild strips of farms 2, 3 and 4; the second cluster involves plots with field margins represented by cultivated strips of farm 4 .

Table 5 shows the $\mathrm{R}$ statistic of the analysis of similarity (Cluster analysis) for species diversity and richness. All the three groups (1, 2: $\mathrm{R}=0.025 ; 1,3: \mathrm{R}=0.333 ; 2,3 \mathrm{R}:=0.32)$ have a $\mathrm{R}$ statistic value that is higher than zero and this confirms that the difference between field margins is verified. The comparison between group 1and 3 has a higher $\mathrm{R}(0.333)$ and this confirms the different ecological value of wild margin strips with hedgerow and cultivated margin strips.

Carabid insects. As regard to carabid insects, the most indicative analysis was the CA applied to richness and diversity which distributed plots in three clusters: the first cluster includes plots

Table 5. R statistic Anosim test of plant species (year 2005).

\begin{tabular}{ccc}
\hline Group & R statistic & Level \\
\hline 1,2 & 0.025 & 36.5 \\
1,3 & 0.333 & 40.0 \\
2,3 & 0.320 & 16.7 \\
\hline
\end{tabular}


Figure 4. Cluster analysis (CA) of plant richness and diversity species in field margins of the four studied farms (year 2005) based on the Bray-Curtis similarity coefficient $(\mathrm{MDS}=0.01)$.

Figure 5. Claster analysis (CA) of Carabid beetles richness and diversity in field margins of the four studied farms (year 2004) based on the Bray-Curtis similarity coefficient $(\mathrm{MDS}=0.01)$.
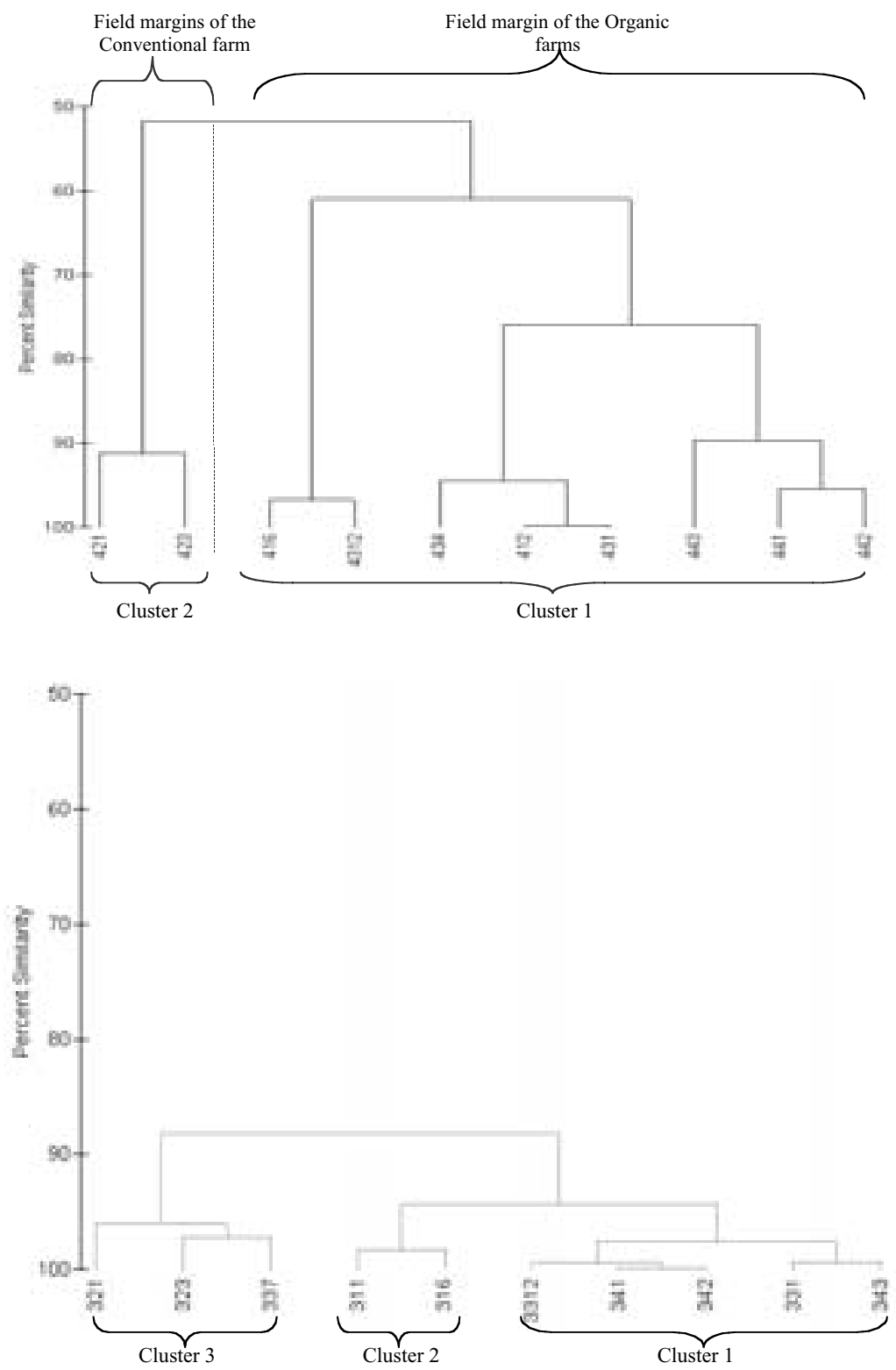

with field margins represented by old sown grass strips in farm 2 and field margins with hedgerow and wildflower strips in farm 4; the second cluster includes plots of field margins with sown grass strips in farm 3; the third cluster includes plots of field margins with cultivated strip of farm 1 and 4 (Fig. 5).

Table 6 shows the $\mathrm{R}$ statistic of the analysis of similarity (Cluster analysis) for the diversity and richness of carabid beetles. Two of the three groups $(1,2 \mathrm{R}=0.669 ; 1,3 \mathrm{R}=0.583)$ have a $\mathrm{R}$ statistic value that is higher than zero and this confirms the different effects of the studied field margins. The comparison between 1 and 3 has a higher R (0.583) and this confirms the difference between wild margin strips with hedgerow and cultivated margin strips; at the contrary, the comparison between group 2 and 3 has a negative $\mathrm{R}(-0.16)$ confirming a similar effects of the two typologies of field margins: grass margin strips and wild margin strips with hedgerow.

PCA for single species does not show a clear difference between plots with sown grass or wild margin strips and those with cultivated strips. 
Table 6. R statistic Anosim test of carabid beetles (year 2004).

\begin{tabular}{ccc}
\hline Group & R statistic & Level \\
\hline 1,2 & 0.669 & 0.8 \\
1,3 & 0.583 & 20.0 \\
2,3 & -0.160 & 66,7 \\
\hline
\end{tabular}

\section{Conclusions}

The whole analysis carried out leads to the conclusion that the studied area, Val d'Orcia, is very poor in biodiversity and therefore, it is necessary to improve the planned biodiversity introducing new ecological infrastructures represented by complex or simple field margins. There is evidence that organic farming could play a significant role in implementing biodiversity, especially by increasing the quality and quantity of non cropped habitats and boundaries. The presence of sown grass or wild strips managed by the farmer has great importance in increasing biodiversity of flora and fauna (insects) species.

The more complex the field margins are, for example with tree, hedgerows or wildflower or sown grass strips, the more positive the effects are. The statistic analysis of biodiversity confirms a clear positive influence of plots with field margins with sown strips.

PCA shows a cluster of species living in complex field margins. Fields margins with sown or wild strip give the same benefits also for the indicators "carabid beetles", both for its richness and diversity.

These results confirm that there is a relationship between planned biodiversity, crops and even simple field margins with sown strips, and the increasing of associated biodiversity (Vandermeer and Perfecto, 1995; Altieri et al., 2003). The careful adoption of specific management practices is necessary to sustain optimal levels of such biodiversity.

\section{Acknowledgements}

The present research is part of the research project financed by the Agricultural Ministry (MIPAF), whose title is "The importance of wild fauna to improve territorial and agricultural researches". Thanks to Roberto Vivoli and Giovanna Casella for their help in collecting data and to farmers from Val d'Orcia who permitted to carry out the research in their farms and particularly to Francesco Simonelli for his kindness and availability.

\section{References}

Aalto V. 1998. The diversity of the flora and the structure of the vegetation on organically and conventionally farmed field margins. University of Helsinki, Helsinki.

Altieri M.A., Nicholls C.I., Ponti L. 2003. Biodiversità e controllo dei fitofagi negli agroecosistemi, Accademia Nazionale Italiana di Entomologia, Firenze.

Bray J.R., Curtis J.T. 1957. An ordination of the upland forest communities of Southerm Wisconsin. Ecol. Monogr., 27:325-349.

Catizone P., Zanin G. 2001. Malerbologia. Patron, Bologna.

Clarke K.R., Warwick R.M. 1994. Change in marine communities: an approach to statistical analysis and interpretation. Plymouth Marine Laboratory, Natural Environmental Research Council, UK, 144.

Chatfied C., Collins A.J. 1980. Introduction to multivariate analysis. Chapman and Hall, London.

Feber R. 1998. The effects of organic and conventional farming system on the abundance of butterflies. In: Report to WWF (UK) - Project 95/93 - Plants and Butterflies: Organic farms. Wildlife Conservation Research Unit. Dept. of Zoology Oxford in collaboration with SAFE Alliance \& Butterfly Conservation, Oxford.

Frieben B., Kopke U. 1995. Effect of farming system on biodiversity. In: Isart J., Llerena J.J. (eds.): Proceeding of ENOF Workshop - Biodiversity and Land Use: Organic Farming. Multitex, Barcelona, 11-29.

Greaves M.P., Marshall E.J.P. 1987. Field margin: definitions and statistic. In: Way, J.M., Greig Smith P.J. (ed.): Field Margins, Monograph, N. 35. British Crop Protection Council, Thornton Heath, Surrey, UK, 310.

Hald, A.B. 1999. Weed vegetation (wild flora) of long established organic versus conventional cereal fields in Denmark. Annals of Applied Biology, 134:307-314.

Helenius J., Holopainen K., Muhojoki M., Pokki P., Tolonen T., Venalainen A. 1995. Effects of undersowing and green manuring on abundance of ground beetles (Coleoptera, Carabidae) in cereals. Acta Zoologica Fennica, 196:156-159.

Hole D.G., Pekin A.J., Wilson J.D., Alexander I.H., Grice P.V., Evans A.D. 2005. Does organic farming benefit biodiversity? Biological Conservation, 122:113-130.

Kromp B. 1999. Carabid beetles in sustainable agriculture: a review on pest control efficacy, cultivation impacts and enhancement. Agriculture, Ecosystems and Environment, 74:187-228.

Lazzerini G., Colom M.R., Camerà A., Sacchetti P., Vazzana C. 2004. Biodiversità aziendale e sua relazione con gli aspetti gestionali in aziende biologiche e convenzionali in Val d'Orcia in Toscana. XIV Congresso Nazionale Società Italiana di Ecologia, 4-6 ottobre 2004, Siena.

Lewis T. 1965. The effects of shelter on the distribution of insect pests. Scientific Horticulture, 17:74-84. 
Marshall E.J.P. 1995. Research on field margin boundary strips: identifying goals and developing appropriate techniques. In: Jorg E. (ed.): Field margin strip programmes. Proceedings of a technical seminar. Landsanstalt für Pflanzenbau und Pflanzenschutz, Mainz, Germany, 16-26.

Montegut J. 1982. Perennes et Vivaces Nuisibles en Agriculture. SECN, Aubervilliers, France, 414.

Moonen A.C., Marshall E.J.P. 2001. The influence of sown margin strips, management and boundary structure on herbaceous field margin vegetation in the neighbouring farms in southern England. Agriculture, Ecosystems and Environment, 86:187-202.

Nentwing W. 1988. Augmentation of beneficial arthropods by strip management. 1 . Succession of predaceous arthropods and long-term change in the ratio of phytophagous and predaceous species in a meadow. Oecologia, 76:597-606.

Rabb R.L. 1978. A sharp focus on insect populations and pest management from a wide area view. Bulletin of the Entomological Society of America, 24:5560 .

Shannon C.E., Weaver W. 1963. The Mathematical Theory of Communication. University of Illinois Press, Urbana, 117.

Soil Association 1999. Standards for organic food and farming. Soil Association, Bristol

Sotherton N.W. 1984. The distribution and abundance of predatory arthropod over wintering on farmland. Ann. Appl. Biology, 105:423-424.

Southwood T.R.E., Way M.L. 1970. Ecological background to pest management. In: Rabb R.L., Guthrie F.E. (eds.): Concepts of pest management. North Carolina State University, Raleigh NC.

Sunderland K., Samu F. 2000. Effects of agricultural diversification on the abundance, distribution, and pest control potential of spiders: a review. Entomologia Experimentalis et Applicata, 95:1-13.

Thomas C.F.P., Marshall E.J.P. 1999. Arthropod abundance and diversity in differently vegetated margins of arable fields. Agriculture, Ecosystems and Environment, 72:131-144.

Thomas M.B., Wratten S.D. 1990. Ecosystem diversification to encourage natural enemies of cereal aphids, 691-696. I pests and disease, Brighton Crop Protection Conf.

Vandermeet J., Perfecto I. 1995. Breakfast of biodiversity. Food First Books, Oakland, California, UK.

Vazzana C., Raso E. 1997. Una metodologia europea per la progettazione e realizzazione di un agroecosistema a basso o nullo impatto ambientale. SITE Notizie, Bollettino della Società Italiana di Ecologia, XVII, numero unico, 51-54.

Verejiken P. 1995. Designing and testing prototypes: Progress report n. 2 of the research network on integrated and ecological arable farming system for UE and associated countries. Wageningen (NL), AB-DLO. 